\title{
SISTEMAS AUTOMATIZADOS EM URINÁLISE: APLICAÇÃO NA ROTINA LABORATORIAL DAS NOVAS TECNOLOGIAS
}

\section{AUTOMATED SYSTEMS IN URINALYSIS: APPLICATION IN THE LABORATORY ROUTINE OF NEW TECHNOLOGIES}

\author{
Julia Midori Endo NAKASATO', Gislene KUSSEN², Aline Borsato HAUSER ${ }^{3}$
}

1 - Laboratório de Análises Clínicas - Prefeitura de São José dos Pinhais - PR

2 - Serviço de Bacteriologia da Unidade do Laboratório de Análises Clínicas do Complexo Hospital de Clínicas, Universidade Federal do Paraná

3 - Departamento de Análises Clínicas, Curso de Farmácia, Universidade Federal do Paraná

Autor para correspondência: alinehauser@ufpr.br

\section{RESUMO}

O parcial de urina é um exame simples e rápido com informações importantes sobre o funcionamento dos rins e do trato urinário. A introdução de novas tecnologias aumentou a exatidão e a produtividade, no entanto, a falta de padronização e a escassez de informação técnica são fatores limitantes que podem comprometer a interpretação do exame. O objetivo deste trabalho foi ampliar o conhecimento sobre automação em urinálise e torná-la mais consistente na prática laboratorial. Foram abordados os sistemas semi- automatizados, exame microscópico automatizado por citometria de fluxo, imagem digital com reconhecimento de partículas, sistema modular misto, microscopia digital com contraste de fase, além dos novos parâmetros: relação albumina/creatinina e proteína/creatinina. Foi observado que a automação da análise química evita as discrepâncias entre resultados e os erros analíticos nos métodos convencionais e que, a análise microscópica automatizada melhora a reprodutibilidade e permite uma maior padronização, no entanto, a liberação automática ou a necessidade de revisão microscópica serão definidas pela equipe profissional. Foi concluído que os diferentes sistemas de automação apresentam vantagens e desvantagens e a escolha do método depende do porte do laboratório, do custo-benefício e da população atendida com foco na confiabilidade dos resultados para um diagnóstico correto.

Palavras-chave: laboratório de análises clínicas, urinálise, automação, parcial de urina

\section{ABSTRACT:}

The urine is a simple and quick examination with important information about the kidney function and urinary tract. The introduction of new technologies has increased accuracy and productivity; however, the lack of standardization and the lack of technical information are limiting factors that can compromise the interpretation of the exam. This work sought to broaden the knowledge about automation in urinalysis and to make it more consistent in laboratory practice. The techniques analyzed were semiautomated, automation of the microscopic examination - flow cytometry, digital image with particle recognition, mixed modular system, digital microscopy with phase contrast, and the new parameters albumin/creatinine and protein/creatinine. It was observed that the automation of the chemical analysis avoids the discrepancies between results and the analytical errors in the conventional methods and that, the automated microscopic analysis improves the reproducibility and allows a greater standardization, nevertheless, the automatic release or the need for microscopic review will be defined by the professional team. It was concluded that the different automation systems have advantages and disadvantages and the choice of method depends on the size of the laboratory, the cost-benefit and the population served, focusing on the reliability of the results for correct diagnosis.

Key words: clinical laboratory, urinalysis, automation 


\section{INTRODUÇÃO}

O exame parcial de urina representa um dos exames mais solicitados na rotina dos laboratórios de análises clínicas. Essa alta demanda nos laboratórios atuais se deve ao fato da análise da urina ser capaz de fornecer, de forma simples e rápida, informações importantes sobre o funcionamento dos rins e do trato urinário.

O parcial de urina é um exame realizado de forma manual em grande parte dos laboratórios e há décadas, a análise microscópica do sedimento urinário é considerada padrão ouro na urinálise. No entanto, a introdução de novas tecnologias tem aumentado a exatidão e a produtividade desse procedimento (BOTTINI, 2006) (DELANGHE, 2014).

Apesar dos analisadores automatizados representarem uma melhora em termos de qualidade dos resultados emitidos, com redução significativa no tempo necessário para sua execução, a falta de padronização e a escassez de informação técnica a respeito das novas tecnologias empregadas são fatores limitantes para sua utilização.

Dentro desse contexto, o objetivo deste trabalho foi ampliar o conhecimento sobre automação em urinálise e torná-la mais consistente na prática laboratorial, apresentando uma análise dos sistemas automatizados disponíveis para compará-las entre si, por meio da compilação de trabalhos publicados, manuais de equipamentos e da experiência profissional, a fim de avaliar e comparar seus desempenhos e estabelecer as perspectivas para o melhor auxílio no diagnóstico das doenças renais e do trato urinário.

\section{BREVE HISTÓRICO}

O exame de urina deu origem à medicina laboratorial e ainda hoje é considerado um método ideal por se tratar de um fluido instável que sofre mudanças quando a doença se instala. Os primeiros relatos foram encontrados em papiros do Antigo Egito e com o surgimento da microscopia, Thomas Addis instituiu o método de contagem de elementos urinários. Na década de 60 , foi lançada a tira reativa com múltiplos parâmetros para a análise química (BLAGG, 2009) (BARDALES, 2002) (KAMALEDEEN, 2015) (ROCHE, 2018). Ao longo do tempo, ocorreram avanços nas técnicas de impregnação nas áreas reagentes, aumento da estabilidade dos indicadores de cor e aperfeiçoamento na graduação das cores, o que contribuiu para sua disseminação como instrumento diagnóstico confiável. $O$ início da automação em urinálise se deu com o surgimento dos leitores das tiras reativas e, atualmente, o exame de urina pode ser realizado por método 
manual, semi-automatizado ou totalmente automatizado (MUNDT, 2012) (STRASINGER, 2014) (ABNT 15.268, 2005).

\section{EXAME QUÍMICO E SISTEMAS SEMI-AUTOMATIZADOS}

A leitura visual das tiras reagentes pode levar a diferenciação das cores entre indivíduos, sofrer influência da luz no ambiente, declínio na intensidade da cor e dificuldade em utilizar o tempo correto de reação. Rumley (2000) mostrou uma comparação entre leitura visual e através do leitor de tiras (CLINITEK 50 - Bayer®) onde foram observados resultados diferentes entre analisadores pela leitura visual se comparados aos resultados do leitor (RUMLEY, 2000). Portanto, o equipamento permite maior padronização evitando medições erradas que ocasionem falhas na decisão médica, especialmente no controle de glicose e proteína na urina (ROCHE, 2010).

O método dos leitores de tiras é o da fotometria por reflectância (Figura 1), onde a medição da intensidade de luz ocorre a partir de uma fonte luminosa. A luz refletida da área reagente é comparada à luz refletida por uma superfície de referência. A conversão do valor medido de parâmetro não linear para linear se dá pela equação de Kubelka-Munk ou transformação de Clapper-Williams (BURTIS, 2016). A fonte de luz utilizada é o light emitting diodes (LED) com tempo de medição ajustado que permite precisão nas mínimas alterações de cor. A fonte de LED emite luz em comprimento de onda específico capturada pelo detector como sinal elétrico analógico para um conversor $A / D$ que converte em sinal digital. Os valores de reflectância são comparados com intervalos de medição definidos por calibradores gerando resultados semi-quantitativos e para eliminar a interferência da cor intrínseca da urina, existe uma zona de compensação (ROCHE, 2018). Atualmente, foram adicionados sistemas ópticos capazes de digitalizar a imagem e transmiti-la para sensores capazes de realizar as leituras de cor com maior precisão. E, mais recentemente, sensores de cor com a tecnologia semi-condutor de óxido de metal complementar (CMOS) que permitem a distinção da reação de cor entre hemácias íntegras e hemoglobina livre (SYSMEX, 2017).

\subsection{Automação do Exame Microscópico Citometria de Fluxo}

A citometria de fluxo tem como finalidade "medir" as células individualmente que passam através de uma câmara de contagem (citômetro) arrastadas por um fluxo constante 
de um líquido condutor de eletricidade. As células são más condutoras de eletricidade e ao passarem modificam a diferença de potencial gerando sinal proporcional ao tamanho da célula - bioimpedância. Quanto maior a célula, mais longa a diferença de potencial e maior a bioimpedância. Atrás da fonte do laser e da câmara de fluxo existe um detector de luz frontal (dispersão frontal) que avalia o tamanho da célula. Nos equipamentos hematológicos, há uma lente convergente que direciona a luz desviada lateralmente (dispersão lateral), que fornece informação sobre o conteúdo celular (núcleo e grânulos). Na urinálise esta informação apresenta limitações devido às características da urina, que não é constituída apenas por células, mas também por cristais, cilindros, bactérias, fungos, parasitas e outros artefatos (SOARES, 2012) (HENNEBERG, 2014). Assim surgiu a fluorescência, que permite que as estruturas internas sejam marcadas com fenantridina para ácidos nucléicos (alaranjada) e carbocianina para membranas celulares (esverdeada), com geração de gráficos de dispersão e histogramas. Dessa forma, os elementos urinários são classificados conforme volume (impedância), tamanho (dispersão de luz) e características tintoriais (fluorescência) (BOTTINI, 2006) (MUNDT, 2012) (HENNEBERG, 2015). Conforme Figura 1 (B), o dispersograma analisa os dados conforme a altura dos sinais de intensidade de fluorescência versus altura dos sinais de luz dispersa frontal identificando hemácias, leucócitos e bactérias. Já as células epiteliais, cilindros sem inclusão e cilindros patológicos (com inclusões) são classificados conforme a largura do pulso de fluorescência versus largura do pulso de dispersão frontal. A grande dificuldade da citometria de fluxo é a elevada taxa de revisão (50-60\%), uma vez que não é capaz de diferenciar diversos elementos e 0 analista obriga-se a realizar a microscopia do sedimento urinário. Foi também observado que amostras com contagens elevadas de microrganismos (bactérias, leveduras) apresentaram maior tendência a erros na detecção de eritrócitos e que, a presença de quantidades elevadas de células redondas pequenas pode interferir nas contagens de leucócitos (WESARACHKITTI, 2016).

\subsection{Imagem Digital com Reconhecimento de Partículas}

O método desenvolvido por meio de uma câmera digital de alta definição acoplada a uma lente de microscópio óptico capaz de fotografar a imagem dos elementos urinários trouxe uma grande evolução na área de urinálise. O equipamento $\mathrm{Q} \AA^{\circledR 200}$ (Iris Diagnostics) utiliza microscopia automatizada com reconhecimento de partículas e para análise completa pode ser acoplado ao aparelho AUTION MAX® para análise química (MUNDT, 2012). Sob a influência da citometria de fluxo é utilizada tecnologia da morfologia de fluxo digital 
(DFM) que alinha os elementos para serem fotografados por câmera digital. A amostra de urina (não centrifugada) é aspirada e colocada em um sistema que gera uma camada única em fluxo laminar que se desloca ao longo da lente objetiva do microscópio do aparelho. Uma câmera digital, iluminada por uma luz estroboscópica, captura 500 quadros por amostra. O software Auto- ParticleRecognition $\AA$ identifica os elementos comparando tamanho, forma, contraste e textura, graças ao uso de redes neurais computadorizadas, compostas por um arquivo semelhante à memória humana, com inúmeras imagens em seu banco de dados. São identificadas as seguintes estruturas: eritrócitos, leucócitos, bactérias, cilindros hialinos, cilindros patológicos, cristais, células epiteliais escamosas, células epiteliais não escamosas, leveduras, espermatozóides e muco. A avaliação conclusiva dessas imagens digitais deve ser realizada por um profissional experiente (MUNDT, 2012) (BECKMAN COULTER, 2014).

\subsection{Microscopia Automatizada com Imagem Digital}

Em seguida, surgiu o sistema de microscopia automática com imagem digital conforme Figura 1 (D), onde ocorre homogeneização e pipetagem de uma alíquota da urina que após centrifugação automatizada, forma a camada de sedimento, no interior de um dispositivo (cuvete) que simula a tradicional lâmina e lamínula, com vários campos fotografados (15 a 20) por uma câmera digital, como nos campos observados ao microscópio. As partículas são categorizadas conforme tamanho e forma, usando um software processador de imagens módulo automático de avaliação de imagem (AIEM), de alta qualidade, capaz de reconhecer: eritrócitos, leucócitos, cilindros hialinos, cilindros patológicos, células epiteliais escamosas, células epiteliais não escamosas, bactérias, leveduras, cristais (oxalato de cálcio monohidratado, oxalato de cálcio diidratado, ácido úrico, fosfato triplo), muco, espermatozóides e permite a reclassificação manual pelo profissional em caso de discordância. Os equipamentos UriSed®II (AlereTM) e Cobas® 6500 (ROCHE), utilizam essa tecnologia e quando o UriSed®II é acoplado ao LabUMat@II para análise química, tem-se o sistema totalmente automatizado. O equipamento Cobas ${ }^{\circledR} 6500$ é formado pelo módulo 601 com análise físico-química e 701 com sedimento urinário (URISED, 2014) (77 ELEKTRONIKA, 2018) (ROCHE, 2013) (BLOCK, 2012).

\subsection{Sistema Modular Misto}

A empresa Sysmex® lançou em 2017 a Série-um, que pode ser enquadrada como 
um sistema modular misto. O sistema modular UN-3000 é composto por três módulos distintos: UC-3500TM para análise química com nova tecnologia de fotometria com sensor inteligente de cor CMOS que digitaliza a tira para distinguir com mais facilidade a coloração, UF-5000TM para análise de partículas com tecnologia de citometria de fluxo fluorescente, e UD-10TM para análise de partículas por meio de imagem digital, com uma câmera acoplada de alta definição que classifica as partículas e armazena de 40-80 imagens para revisão pelo analista (SYSMEX, 2017).

\subsection{Microscopia Digital com Contraste de Fase}

Ainda indisponível no Brasil, o Urised®3 PRO (77 Elektronika), traz como proposta a análise do sedimento urinário incorporando a microscopia com contraste de fase na avaliação dos elementos urinários. Por meio dessa tecnologia, pretende-se melhorar a visualização e a capacidade de reconhecimento em relação ao uso isolado da microscopia em campo claro, principalmente para aqueles elementos que não seriam facilmente detectados, tais como cilindros e hemácias fantasmas (77 Elektronika, 2018).

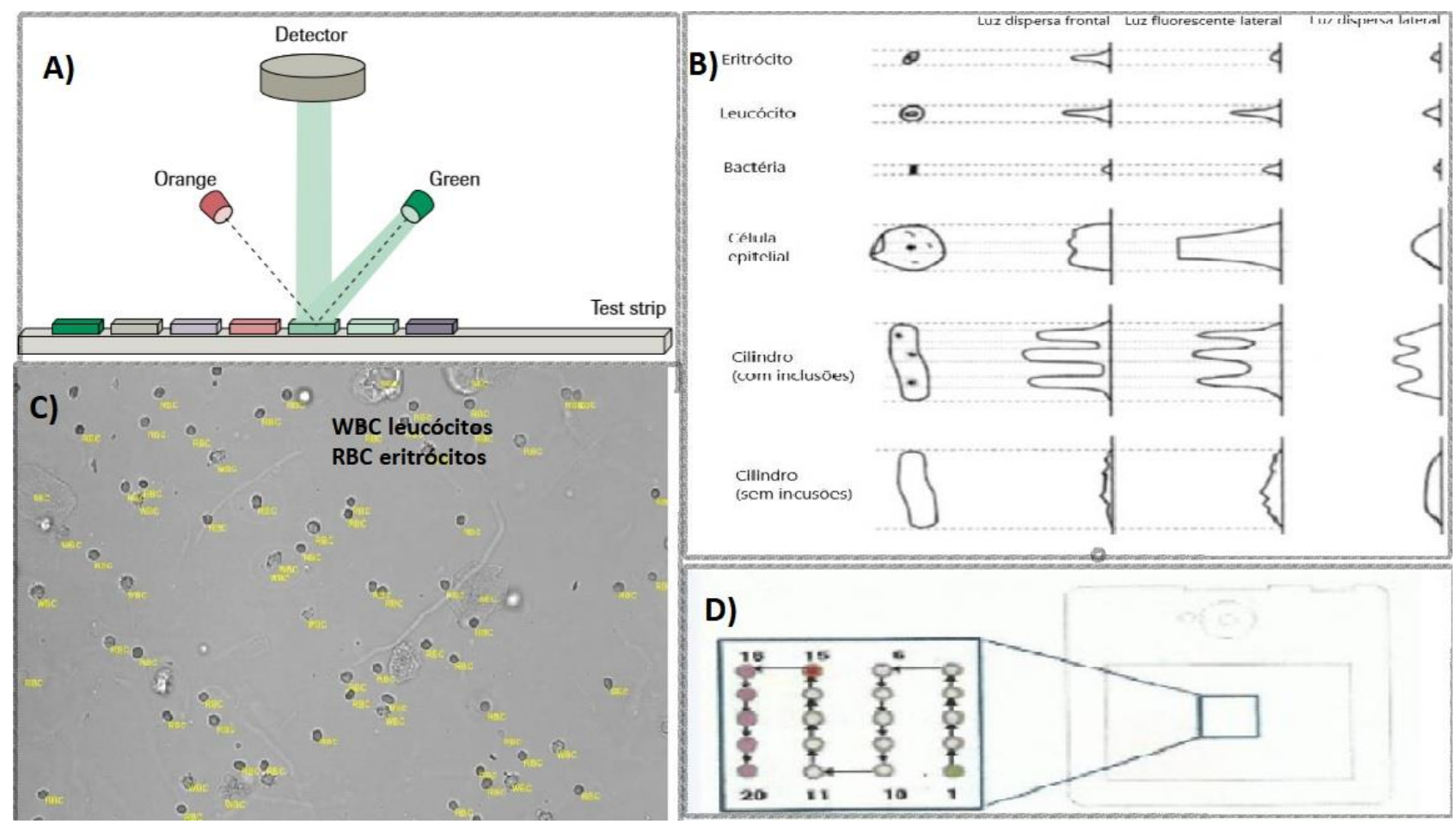

Figura 1. Exemplos de Tecnologias para Automação: A) Reflectância para Tira Reativa, B) Microscopia por Citometria de Fluxo, C) Microscopia por Imagem Digital, D) Cuvete para Automação Fonte: Imagens adaptadas pelas autoras (UCL, 2016; ROCHE, 2010). 


\subsubsection{Considerações sobre Análise Microscópica Automatizada}

O European Confederation of Laboratory Medicine (ECLM) recomenda atenção ao fato da etapa de centrifugação, que pode representar fonte de erro analítico associado ao fato da urina ser uma solução coloidal heterogênea (EUG, 2000). Lembramos que nos métodos manuais a centrifugação com remoção do sobrenadante é utilizada como ferramenta para concentração dos elementos no sedimento urinário, enquanto que em alguns métodos de automação, é utilizada a urina não centrifugada favorecendo a padronização e evitando a perda de elementos no sobrenadante.

Apesar dos relatos de perda de precisão nas contagens quando outros elementos são encontrados em grande quantidade (MUNDT, 2012) (HENNEBERG, 2015), a quantificação automatizada permite maior precisão quando comparado aos métodos manuais, nos diferentes métodos automatizados, tendo em vista o número maior de elementos contados pelos equipamentos. Entretanto, ainda se notam dificuldades na identificação de certos elementos urinários tornando necessária a revisão da amostra por análise microscópica tradicional. A vantagem observada pelos sistemas que realizam a captura de imagem digital é a possibilidade de revisão pelo analista nas imagens armazenadas na memória do aparelho. Isso reduz a taxa de revisão de amostras pelo método convencional de microscopia para cerca de 10-20\% (WESARACHKITTI, 2016). Apesar disso, os sistemas que utilizam a microscopia automática com imagem digital são prejudicados pelas limitações na diferenciação de células anormais (eritrócitos dismórficos ou fantasmas, leucócitos danificados, células fragmentadas) ou elementos como diferentes cristais e cilindros com inclusões, além de serem imprecisos na definição de estruturas semelhantes entre si, tais como eritrócitos e leveduras, ou bactérias e cristais amorfos. Outras situações que não são facilmente distinguidas pela microscopia automatizada são a presença de gotículas de gordura, células pequenas redondas, Trichomonas sp. e outros parasitas que podem ser encontrados na urina humana. Esses elementos são cruciais para o diagnóstico de diversas patologias do sistema urinário e merecem atenção antes da liberação do laudo. Portanto, nenhum dos sistemas disponíveis pode ser considerado auto-suficiente, sendo atualmente incapazes de distinguir com precisão certos elementos com impacto para o diagnóstico do paciente.

De forma geral, a maior vantagem dos aparelhos automatizados é a padronização dos resultados e a realização de grandes rotinas em pouco tempo. A capacidade de processamento dos aparelhos mais robustos permite realizar 100-1000 amostras diárias, o 
que seria impraticável se realizadas pelos métodos manuais (ROCHE, 2018). Além disso, permitem contagens de elementos por unidade de volume, conforme preconizam os guias internacionais (CLSI, 2001; ABNT, 2005; EUG, 2000).

Nos sistemas totalmente automatizados, os módulos para análise química e microscópica são acoplados, permitindo a instalação de sistemas de interface que transmitem os resultados do aparelho para um computador, assim reduzindo possíveis erros pós-analíticos. O processo garante agilidade e rastreabilidade com senha pessoal e intransferível para acesso aos dados. O sistema de interface permite a edição dos parâmetros revisados e o envio para um sistema de gerenciamento, que elabora o laudo final com a assinatura digital do profissional responsável.

\section{NOVOS PARÂMETROS EM URINÁLISE AUTOMATIZADA: RELAÇÃO ALBUMINA/CREATININA EPROTEÍNA/CREATININA}

O analisador UN-3000 (módulo UC-3500) traz a inclusão de parâmetros químicos importantes na triagem do distúrbio renal. O módulo UC-3500 permite o uso da tira reativa MEDITAPE UC-9ª que realiza nove parâmetros (urobilinogênio, hemoglobina, proteína, glicose, cetonas, bilirrubina, nitrito, esterase leucocitária e $\mathrm{pH}$ ) e da MEDITAPE UC-11 ${ }^{\mathrm{a}}$ que além desses, inclui a determinação de creatinina e albumina, graças a tecnologia CMOS que permite a leitura direta para quantificação da microalbuminúria e da creatinina (SYSMEX, 2017). Estes parâmetros têm sido defendidos como possíveis substitutos às dosagens em amostras de urina de 24 horas (SOLORZANO, 2012).

\section{CONCLUSÃO}

Dentro desse contexto fica evidente que o parcial de urina persiste como um importante auxiliar no diagnóstico de patologias do sistema urogenital, e que necessita de atenção na sua execução, observando os critérios fundamentais para sua realização.

A escolha do método depende do porte do laboratório, do custo-benefício e da população atendida, lembrando que a automação da análise química evita as discrepâncias entre resultados emitidos por analistas diferentes e os erros analíticos inerentes aos métodos convencionais e que, a análise microscópica automatizada melhora a reprodutibilidade do exame e permite uma maior padronização. No entanto, ressalta-se a importância de equipe profissional experiente atuando lado a lado para permitir a liberação 
automática ou realizar a revisão microscópica, quando necessária.

É possível ainda estabelecer como perspectiva um aperfeiçoamento desses sistemas automatizados, com ampliação da capacidade de distinção dos elementos urinários pelas redes neurais computadorizadas, para que os resultados obtidos sejam cada vez mais precisos e que contribuam de forma efetiva para o diagnóstico correto do paciente.

\section{REFERÊNCIAS}

ALERE INC. Uroanálise - UriSed@II \& LabUMat@II. Disponível em: <http://www.alere.com/pt/ home/product-details/UroanaliseUriSed.html> Acesso em: 11 de junho de 2017.

ASSOCIAÇÃO BRASILEIRA DE NORMAS TÉCNICAS. NBR 15268: Laboratório Clínico Requisitos e recomendações para exame de urina. Rio de janeiro, 2005.

BARDALES, R. H. From Urine Contemplation to Urine Evaluation: Historical. Oxford University Press, 2002. p1-5.

BECKMAN COULTER. Urinalysis Lab Forward: Take the next step toward urine microscopy, 2014.

BLAGG, CR. Thomas Addis, 1881-1949, clinical scientist, hematologist and pioneering nephrologist: a brief biography. Journal of Nephrology, n.22 Suppl14:115-9, 2009.

BLOCK, D. R.; LIESKE, J. C. Automated urinalysis in the clinical lab. Medical Laboratory Observer, v. 44, n. 10, p. 8, 2012.

BOTTINI, P.V.; GARLIPP, C.R. Urinálise: comparação entre microscopia óptica e citometria de fluxo. Jornal Brasileiro de Patologia Médica Laboratorial, v.42. n.3: 157-162, 2006.

BURTIS, C. A.; BRUNS, D. E. Tietz Fundamentals of Clinical Chemistry and Molecular Diagnostics. Tradução da $7^{a}$ ed. Elsevier, 2016.

CLINICAL LABORATORY STANDARDS INSTITUTE. Urinalysis and Collection, Transportation and Preservation of Urine Specimens: Approved Guideline-Second Edition GP16-A2, v.21, n.19, 2001. 
DELANGHE, J.; SPEECKAERT, M. Preanalytical requirements of urinalysis. Biochemic Medica, v.24: 89-104, 2014.

EUROPEAN URINALYSIS GROUP. European Urinalysis Guidelines. Scandinavian Journal of Clinical Laboratory Investigation, 60:1-96, 2000.

HENNEBERG, J.R.; HENNEBERG, R.; NASCIMENTO, A.J.; KUSSEN, G.; BARRETO, F.C.; HAUSER, A.B. Comparison between Manual Methods and Automated Analyzer iQ200®. International Journal of Laboratory Medicine \& Research. 1:108, 2015.

MUNDT, L.A.; SHANAHAN, K. Exame de urina e de fluidos corporais de Graff. 2 ed. Porto Alegre: Artmed, 2012.

ROCHE DIAGNOSTICS INTERNATIONAL LTD. Cobas® 6500 urine analyzer series: Fully automated urine work area on a modular platform. CH-6343 Rotkreuz, Switzerland, 2013.

ROCHE DIAGNOSTICS LTD. Cobas - Compendium of urinalysis: Urine Test Strip and Microscopy. CH-6343 Rotkreuz, Switzerland, 2010.

ROCHE DIAGNOSTICS LTD. Vitamin C and urine test strips. Handling the impact on erythrocytes and glucose results. Switzerland, 2010 (2).

ROCHE DIAGNOSTICS LTD. Cobas® 6500 urine analyzer series - Manual do operador. Versão 1.0.0. 06998437046, 2014.

ROCHE DIAGNOSTICS LTD. Celebrating 50 years of Combur-Test® strip technology from Roche. Disponível em: <http://www.cobas.com/home/news- room/cobas-stories/50-yearscombur.html> Acesso em: 07 de janeiro de 2018.

RUMLEY, A. Urine dipstick testing: comparison of results obtained by visual reading and with the Bayer CLINITEK 50. Ann Clin Biochem, 37:220-221, 2000.

SYSMEX. Série UN: Sistema modular de automatização da Urinálise. Disponível: www.sysmex.com/ la/pt/Products/Documents/SERIEUN_PT_V03_baixa.pdf. Acesso em: 06/12/2017 
SOLORZANO, G.T.M.; SILVA, M.V.M; MOREIRA, S.R.; NISHYDA, S.K.; KIRSZTAJN, G.M. Relação proteína/creatinina na urina versus proteinúria de 24 horas na avaliação de nefrite lúpica. Jornal Brasileiro de Nefrologia, 64-67,2012.

STRASINGER, S.K.; DI LORENZO, M. S. Urinalysis and body fluids. 6 ed. F A Davis, 2014.

UCL - CLINIQUES UNIVERSITAIRES SAINT-LUC. Sédiment urinaire automatisé: l'approche Laboratoire Central Automatisé. Bruxelas, 2016.

URISED. LabUMat 2 \&UriSed 2 - Complete Urine Laboratory System, 2014.

WESARACHKITTI, B.; KHEJONNIT, V.; PRATUMVINIT, B.; REESUKUMAL, K.; MEEPANYA, S.; PATTANAVIN, C.; WONGKRAJANG, P. Performance Evaluation and Comparison of the Fully Automated Urinalysis Analyzers UX-2000 and Cobas 6500. American Society for Clinical Pathology. Laboratory Medicine. 47:2:124-133, 2016.

77 ELEKTRONIKA. LabUMat 2 \&UriSed 2 - A New Phase with Contrast. Disponível em: <en.e77.hu/products/urine-analyzer/labumat-2> Acesso em: 31 de março de 2018. 